\title{
ASO Visual Abstract: Survival Outcomes Among Patients with Metastatic Breast Cancer: Review of 47,000 Patients
}

\begin{abstract}
Mahsa Taskindoust, $\mathrm{BS}^{1}$, Samantha M. Thomas, $\mathrm{MS}^{2,3,4}$, Sarah Sammons, $\mathrm{MD}^{2,5}$, Oluwadamilola M. Fayanju, MD, MA, MPHS ${ }^{1,2,6,7}$, Gayle DiLalla, MD ${ }^{1,2}$, E. Shelley Hwang, MD, MPH ${ }^{1,2}$, and Jennifer K. Plichta, MD, MS ${ }^{1,2,6} \mathbb{C}_{\mathbb{C}}$

${ }^{1}$ Department of Surgery, Duke University Medical Center, Durham, NC; ${ }^{2}$ Duke Cancer Institute, Durham, NC;

${ }^{3}$ Biostatistics Shared Resource, Duke Cancer Institute, Durham, NC; ${ }^{4}$ Department of Biostatistics and Bioinformatics, Duke University, Durham, NC; ${ }^{5}$ Department of Medicine, Duke University Medical Center, Durham, NC; ${ }^{6}$ Department of Population Health Sciences, Duke University Medical Center, Durham, NC; ${ }^{7}$ Department of Surgery, Durham VA Medical Center, Durham, NC
\end{abstract}

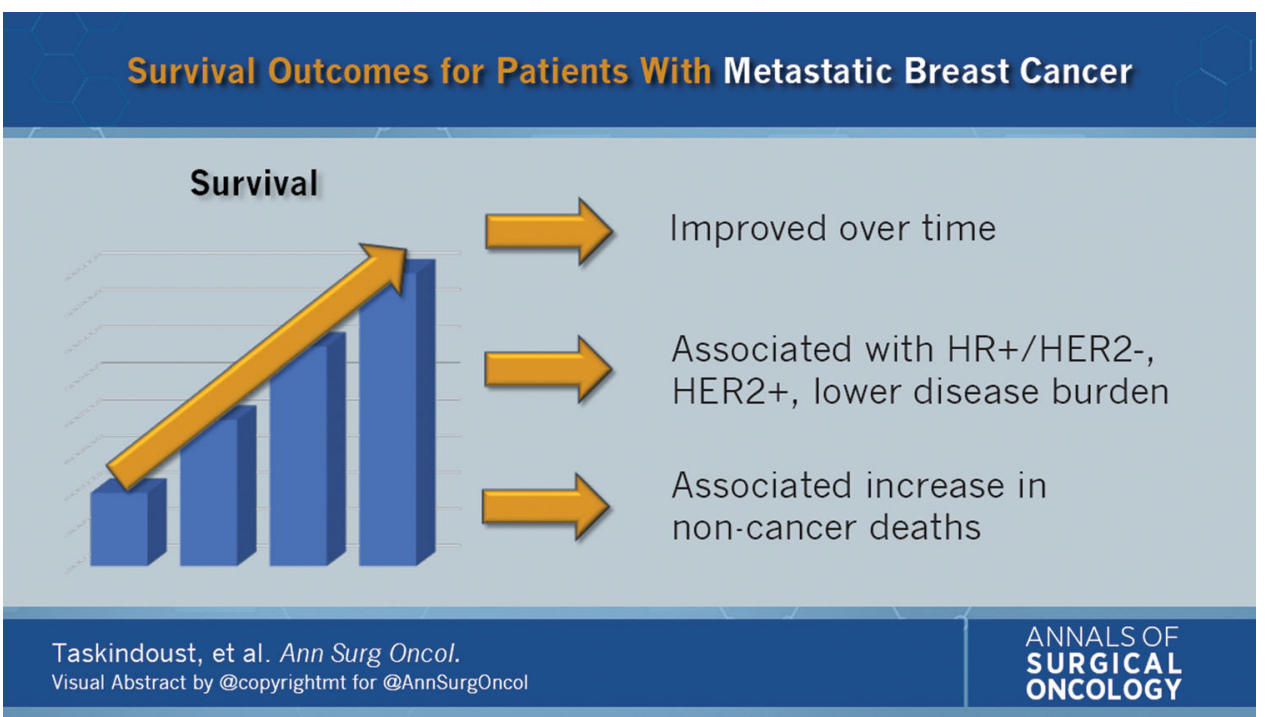

While there is significant heterogeneity, survival outcomes have improved over time for most patients with de novo metastatic breast cancer. For those with limited distant disease and HER2+ or HR+/HER2 - tumors, deaths from noncancer causes are proportionally increasing (https://doi.org/10.1245/s10434-021-10227-3).

Publisher's Note Springer Nature remains neutral with regard to jurisdictional claims in published maps and institutional affiliations.

Podium presentation at the SSO Annual Meeting in March 2021

(C) Society of Surgical Oncology 2021

Published Online: 13 July 2021

J. K. Plichta, MD, MS

e-mail: jennifer.plichta@duke.edu 